\title{
Características de carcaça e qualidade de carne de bovinos inteiros ou castrados da raça Nelore, suplementados ou não durante o primeiro inverno
}

\author{
Carcass characteristics and meat quality of intact or castrated bovines, supplemented or \\ not during the first winter
}

\author{
Saulo Malaguido Climaco ${ }^{1}$ Edson Luis de Azambuja Ribeiro ${ }^{2}$ Marco Antônio da Rocha ${ }^{3}$ \\ Ivone Yurika Mizubuti ${ }^{3}$ Leandro das Dores Ferreira da Silva ${ }^{3}$ \\ Lina Yumi Noro ${ }^{4}$ Tercílio Turini $^{5}$
}

RESUMO

Este trabalho teve como objetivo avaliar características quantitativas e qualitativas da carcaça e da carne de bovinos inteiros e castrados, suplementados ou não durante o primeiro inverno. Foram utilizados 40 bovinos Nelore, machos, inteiros e castrados, com peso inicial e idade média de $300 \mathrm{~kg}$ e 14 meses, submetidos a dois tratamentos: SUP - os animais foram mantidos em pasto e receberam suplementação $(0,5 \%$ do peso vivo) constituída por $25 \%$ de farelo de soja e $75 \%$ de milho em grão triturado, durante o primeiro inverno (01/06/2003 a 21/09/2003); NSU- animais mantidos em pasto, sem suplementação. Após o abate, à idade média de 28 meses, foram avaliadas as características de carcaça. Os animais do tratamento NSU apresentaram maior $(P<0,05)$ percentagem de músculo na carcaça do que os do tratamento SUP $(71,65$ vs $68,53 \%$, respectivamente), porém os animais suplementados apresentaram carnes mais macias $(7,66$ vs 6,41 kgf). Não foram observadas diferenças $(P>0,05)$ quanto à espessura de gordura subcutânea entre animais inteiros e castrados $(2,20 \mathrm{vs} 4,17 \mathrm{~mm}$, respectivamente), porém os castrados apresentaram maior $(P<0,05)$ percentagem de gordura na carcaça $(11,34$ vs 16,68\%) e carnes mais macias (7,50 vs 6,57kgf). Os animais inteiros e os não-suplementados apresentaram medida de gordura de cobertura inferior ao exigido pela indústria.

Palavras-chave: gordura, maciez, marmoreio, músculo.

\section{ABSTRACT}

This research was aimed at evaluating quantitative and qualitative characteristics of the carcass and meat from intact or castrated beef cattle, supplemented or not supplemented during the first winter. Forty Nellore males, intact or castrated, with initial weight and age of $300 \mathrm{~kg}$ and 14 months, were submitted to the treatments: 1) SUP - Animals on pasture and supplemented (0.5\% of the live body weight) with concentrated $(25 \%$ of soybean meal and $75 \%$ of ground corn) during the first winter (06/01/2003 to 09/21/2003), and 2) NSU - Animals on pasture, without supplementation. At slaughter, on an average age of 28 months, the carcass characteristics were evaluated. Animals of the NSU treatment presented the largest $(P<0.05)$ muscle percentage in the carcass, when compared to animals of the SUP treatment $(71.65 \mathrm{vs}$ $68.53 \%$, respectively), however, supplemented animals presented meats with greater tenderness (7.66 vs $6.41 \mathrm{kgf})$. Differences were not observed $(P>0.05)$ for fat thickness between castrated and intact animals (4.17 vs $2.20 \mathrm{~mm}$, respectively), however, castrated animals presented greater $(P<0.05)$ fat percentage in the carcass (16.68 vs $11.34 \%)$ and more tender meat $(6.57 \mathrm{vs} 7.50 \mathrm{~kg})$ than the intact animals. Intact and non-supplemented animals presented backfat thickness lower than required by the industry.

Key words: fat, marbling, muscle, tenderness.

\section{INTRODUÇÃO}

A produção de carne bovina em pastagens depende da qualidade nutricional da dieta oferecida aos animais, principalmente da forragem, e tem seus parâmetros determinados pelas exigências da indústria, que busca atender ao mercado consumidor, seja ele interno ou externo.

De maneira geral, a oscilação na qualidade nutricional das forragens tropicais durante parte do ano justifica a adoção de medidas estratégicas para

\footnotetext{
${ }^{1}$ Programa de Pós-graduação em Ciência Animal, Universidade Estadual de Londrina (UEL), Londrina, PR, Brasil.

${ }^{2}$ Departamento de Zootecnia, UEL, 86051-970, Londrina, PR, Brasil. E-mail:elar@uel.br. Autor para correspondência.

${ }^{3}$ Departamento de Zootecnia, UEL, Londrina, PR, Brasil.

${ }^{4}$ Curso de Zootecnia, UEL, Londrina, PR, Brasil.

${ }^{5}$ Curso de Medicina Veterinária, UEL, Londrina, PR, Brasil.
} 
garantir o aporte de nutrientes essenciais aos animais. A suplementação alimentar objetiva atender às exigências dos animais que passam por períodos de restrição e suprir os déficits energético, protéico, mineral e vitamínico (MÜLLER \& PRIMO, 1986; EUCLIDES FILHO et al., 1997).

A redução da idade ao abate de machos levanta a dúvida quanto à prática ou não da castração. Sabe-se que, no aspecto ganho de peso e eficiência alimentar, há uma manifestação de superioridade dos animais inteiros frente aos castrados, atribuída à ação dos hormônios androgênios produzidos nos testículos. Comparando animais inteiros e castrados, RESTLE et al. (1999) verificaram rendimento de carcaça similar (em torno de 52\%) para animais castrados aos 45 dias, aos 7 meses, aos 12 meses de idade e para animais inteiros. Os inteiros apresentaram melhor conformação do que os castrados, indicando uma maior musculosidade. Os animais castrados mais cedo apresentaram maior valor para a gordura de cobertura. RIBEIRO et al. (2004) verificaram maior peso de abate, maior rendimento de carcaça e maior proporção de músculo na carcaça dos animais inteiros e maior proporção de gordura na carcaça e maior marmoreio nos animais castrados, porém não foram observadas diferenças para força de cisalhamento da carne entre os animais dos dois grupos.

Segundo GERRARD et al. (1987), existe interação entre estado sexual e idade ao abate, influenciando na maciez da carne. Esses autores observaram que os animais castrados apresentaram decréscimo contínuo na maciez da carne com o incremento da idade, enquanto que, nos animais inteiros, houve grandes oscilações com o incremento da idade, com menores valores de força de cisalhamento aos 12 e 18 meses.

Este trabalho teve como objetivo avaliar características quantitativas e qualitativas da carcaça e da carne de bovinos Nelore, inteiros e castrados, suplementados ou não durante o primeiro inverno.

\section{MATERIAL E MÉTODOS}

O experimento foi conduzido em propriedade localizada no município de Nossa Senhora das Graças, região noroeste do Estado do Paraná. Foram utilizados 40 bovinos machos Nelore, com peso inicial e idade média de $300 \mathrm{~kg}$ e 14 meses, respectivamente, sendo que vinte foram castrados 30 dias antes do início do período experimental. Os animais foram divididos em dois tratamentos, com 10 castrados e 10 inteiros por tratamento: "SUP", composto pelos animais que receberam suplementação com concentrado, na proporção de $0,5 \%$ do peso vivo, no período de $01 / 06$ / 2003 a 21/09/2003 (período seco); e "NSU”, composto pelos animais que não receberam suplementação.
O suplemento utilizado foi uma mistura de $75 \%$ de milho grão triturado e $25 \%$ de farelo de soja, com $18 \%$ de PB e $78 \%$ de NDT, fornecido uma vez ao dia (pela manhã) na quantidade de $0,5 \%$ do peso vivo médio do lote, com ajuste a cada 28 dias. Todos os animais foram mantidos em pastagem de Brachiaria brizantha e receberam mistura mineral comercial utilizada na propriedade, ad libitum, durante todo o período experimental. No período da suplementação (inverno), a disponibilidade média de forragem foi de $2.680 \mathrm{~kg}$ de $\mathrm{MS} \mathrm{ha} \mathrm{h}^{-1} \mathrm{e}$, no restante do período experimental, a disponibilidade média foi de $1.620 \mathrm{~kg}$ de MS ha- ${ }^{-1}$. No inverno, a forragem apresentou, na sua composição, em base seca, 4,1\% de PB e $80 \%$ de FDN; no restante do período, a composição foi de $5,3 \%$ de PB e 78,1\% de FDN.

Ao atingirem peso vivo igual ou superior a $480 \mathrm{~kg}$, com idade média de 28 meses, os animais foram abatidos. Após 24 horas em câmara fria a $2^{\circ} \mathrm{C}$, as carcaças foram avaliadas, conforme proposto por MÜLLER (1980), quanto ao peso e rendimento de carcaça fria à conformação de carcaça, ao comprimento de carcaça, ao comprimento de perna, ao comprimento de braço, à espessura de coxão e ao perímetro de braço. No músculo longissimus, entre a $12^{\mathrm{a}}$ e a $13^{\mathrm{a}}$ costela, foram avaliados, de acordo com MÜLLER (1980), a área de olho de lombo, o marmoreio, pontuado de acordo com a distribuição e quantidade da gordura intramuscular em abundante (16 a 18), moderado (13 a15), médio (10 a 12), pequeno (7 a 9), leve (4 a 6 ) e traços (1 a 3); a coloração da carne, pontuada como vermelho-viva (5), vermelha (4), vermelha levemente escura (3), vermelho escura (2) e escura (1); bem como, sobre este músculo, a espessura de gordura de cobertura, tomada a $3 / 4$ do comprimento da área de olho de lombo, a partir da apófise espinhosa (LUCHIARI FILHO, 2000).

Com relação à conformação, as carcaças foram classificadas e pontuadas de acordo com a musculosidade, ou espessura do músculo em relação ao tamanho do esqueleto, em: convexa (6), a mais musculosa; sub-convexa (5), intermediária; retilínea (4), sem arredondamento; côncava(3), com proeminência de apófises ósseas; sub-côncava (2), com cobertura muscular insuficiente e industrial (1), com cobertura muscular muito pobre (ESPEJO et al., 2000).

A composição da carcaça foi estimada, a partir das equações de HANKINS \& HOWE (1946), pela dissecação da porção que compreende as 9-10$11^{\text {as }}$ costelas, sendo obtidas as percentagens de osso, músculo e gordura e relação músculo/osso e porção comestível (músculo+gordura)/osso na carcaça. De acordo com PAULINO et al. (2005), mesmo estas equações tendo sido desenvolvidas para animais de raças européias, elas predizem satisfatoriamente a composição física da carcaça de animais zebuínos. 
A partir de amostra do músculo longissimus, foram feitas análises químicas para determinar a composição da carne dos animais em percentagens de umidade, proteína bruta, extrato etéreo e cinzas, conforme método proposto por SILVA \& QUEIROZ (2002). Amostras deste mesmo músculo foram avaliadas quanto às perdas de água por descongelamento e por cozimento e quanto à maciez. A maciez da carne foi avaliada através da força de cisalhamento, medida pela lâmina Warner-Bratzler-Shear acoplada ao texturômetro.

Os dados foram submetidos à análise de variância (SAS, 1994), sendo considerados os efeitos dos tratamentos (SUP e NSU), do sexo dos animais (inteiros e castrados) e as interações entre estes efeitos, ao nível de $5 \%$ de probabilidade. Foi realizado o estudo de contrastes para comparar animais inteiros suplementados e não-suplementados e animais castrados, suplementados e não-suplementados no primeiro inverno.

\section{RESULTADOS E DISCUSSÃO}

As interações e o estudo de contrastes não mostraram diferenças significativas $(\mathrm{P}>0,05)$. Dessa forma, os resultados são apresentados para os efeitos principais de tratamento (SUP e NSU) e sexo (inteiro e castrado).

Não foram observadas diferenças significativas $(\mathrm{P}>0,05)$ para peso de abate e de carcaça fria dos animais castrados e inteiros e pertencentes aos tratamentos SUP e NSU (Tabela 1). Era esperado que não houvesse diferença entre os pesos de abate dos animais, uma vez que o poso foi pré-determinado. Quanto à composição da carcaça, verificou-se maiores percentuais de músculo na carcaça dos animais pertencentes ao tratamento NSU. Isto ocorreu em função dos valores serem relativos a $100 \%$ e estes animais apresentarem menores proporções de osso e gordura, apesar de não-significativos, conseqüentemente, houve um aumento no percentual de músculo na carcaça.

Os maiores valores de percentagem de músculo na carcaça de animais inteiros e de gordura na carcaça de animais castrados concordam com o que foi verificado por RIBEIRO et al. (2004). Estes resultados estão de acordo com o esperado, pois os animais inteiros estavam sob o efeito anabolizante dos hormônios testiculares. Não foram observadas diferenças nas relações músculo/osso e porção comestível/osso da carcaça.

Comparando características de carcaça de animais inteiros, suplementados ou não durante o período da seca, SANTOS et al. (2002) observaram, além do maior peso de carcaça e espessura de gordura de cobertura, uma melhor relação músculo/osso e menor proporção de osso na carcaça dos animais suplementados, comparados aos não-suplementados, sendo estes últimos abatidos a uma idade mais avançada. MÜLLER \& PRIMO (1986) observaram carcaças de melhor qualidade quanto ao desenvolvimento muscular, àdeposição de gordura e proporção de ossos para os animais que receberam pastagem cultivada de azevém (Lolium multiflorum) durante o inverno, quando comparados com os que receberam apenas pastagem natural.

MOLETTA\& PEROTTO (1998) observaram maior desenvolvimento muscular na carcaça de animais inteiros quando comparados com animais castrados a diferentes idades; entre os castrados, melhores resultados foram obtidos com os animais castrados mais tarde.

Não houve diferença estatística $(\mathrm{P}>0,05)$ para espessura de gordura, sendo que os valores médios para os animais castrados $(4,17 \mathrm{~mm})$ foram

Tabela 1 - Pesos de abate (PA) e carcaça fria (PCF), percentagens de músculo, osso e gordura na carcaça, relação músculo/osso (M/O) e porção comestível/osso (PC/O) na carcaça de acordo com o tratamento e o sexo.

\begin{tabular}{|c|c|c|c|c|c|c|c|}
\hline Efeito & PA $(\mathrm{kg})$ & $\mathrm{PCF}(\mathrm{kg})$ & Músculo $^{*}(\%)$ & Osso $^{*}(\%)$ & Gordura $^{*}(\%)$ & $\mathrm{M} / \mathrm{O}^{*}$ & $\mathrm{PC} / \mathrm{O}^{*}$ \\
\hline \multicolumn{8}{|l|}{ Tratamento } \\
\hline SUP & 488,71 & 255,19 & $68,53^{\mathrm{b}}$ & 16,62 & 14,86 & 3,29 & 4,05 \\
\hline NSU & 489,71 & 253,39 & $71,65^{\mathrm{a}}$ & 15,56 & 13,16 & 3,70 & 4,36 \\
\hline Probabilidade & 0,9264 & 0,7575 & 0,0465 & 0,3008 & 0,2958 & 0,2011 & 0,4909 \\
\hline \multicolumn{8}{|l|}{ Sexo } \\
\hline Inteiro & 497,08 & 252,87 & $72,11^{\mathrm{a}}$ & 16,59 & $11,34^{\mathrm{b}}$ & 3,44 & 3,94 \\
\hline Castrado & 481,33 & 255,72 & $68,07^{\mathrm{b}}$ & 15,59 & $16,68^{\mathrm{a}}$ & 3,55 & 4,47 \\
\hline Probabilidade & 0,1834 & 0,6464 & 0,0161 & 0,3286 & 0,0286 & 0,7328 & 0,2563 \\
\hline $\mathrm{CV}(\%)^{* *}$ & 4,59 & 4,78 & 3,11 & 9,90 & 23,22 & 13,88 & 16,64 \\
\hline
\end{tabular}

${ }^{a, b}$ Médias seguidas de letras diferentes na coluna, para o mesmo efeito, diferem $(\mathrm{P}<0,05)$ pelo teste $\mathrm{F}$.

${ }^{*}$ Calculados segundo equações de Hankins \& Howe (1946).

Coeficiente de variação. 
superiores ao mínimo exigido pela indústria (3,0mm), enquanto que os animais inteiros $(2,20 \mathrm{~mm})$ não atingiram este limite (Tabela 2). A explicação mais provável para não ter ocorrido diferença estatística, apesar das médias serem bem diferentes, é a grande variabilidade dos dados, em que o coeficiente de variação observado foi de $100 \%$. Esses resultados são semelhantes aos obtidos por RESTLE \& VAZ (1997), que não verificaram diferenças entre inteiros e castrados, porém esses autores obtiveram médias acima do limite mínimo para os dois estados sexuais, o que pode ser atribuído à utilização de uma dieta com elevada densidade energética durante o período experimental. MACEDO et al. (2001) não observaram diferenças para espessura de gordura em animais inteiros, terminados a pasto e em confinamento $(0,89$ e $1,89 \mathrm{~mm}$, respectivamente), encontrando-se ambos abaixo do limite mínimo.

Para a área de olho de lombo, não foram observadas diferenças significativas $(\mathrm{P}>0,05)$ (Tabela 2). Porém, foi verificada maior área de olho de lombo para cada $100 \mathrm{~kg}$ de carcaça dos animais inteiros em relação aos castrados. RODRIGUEZ et al (2001) obtiveram correlações positivas e significativas entre peso vivo e área de olho de lombo para bovinos, que indicaram incrementos na área de olho de lombo à medida que aumentavam os pesos-vivo dos animais.

Para as medidas de carcaça, verificaram-se diferenças $(\mathrm{P}<0,05)$ entre os animais no tratamento SUP e os do tratamento NSU apenas para o comprimento de braço, sendo maior no tratamento SUP (Tabela 3). Segundo PACHECO et al. (2005), o comprimento de braço apresenta correlação significativa com outras características métricas, como comprimentos de carcaça e perna, características estas que podem ser influenciadas pelo plano nutritivo, características raciais e sexuais. Resultados similares foram observados por EUCLIDES FILHO et al. (1997), que também não verificaram diferenças para comprimento de carcaça de animais que receberam ou não suplemento durante o período seco.

Entre os sexos, a única diferença observada foi para comprimento de carcaça, uma vez que os inteiros apresentaram maior comprimento do que os castrados, apesar destes valores não conferirem diferentes pontuações de conformação das carcaças (Tabela 3). RESTLE et al. (1994) também verificaram maior comprimento de carcaça para animais inteiros, não havendo diferenças significativas entre carcaças de animais inteiros e castrados quanto à conformação.

Para as características qualitativas da carne apresentadas na tabela 4, pode-se observar que houve diferença apenas para a força de cisalhamento. Foram observados menores valores de força de cisalhamento para os animais do tratamento SUP. Isto ocorreu, provavelmente, em função de os animais suplementados terem apresentado, apesar de não-significativos, maiores percentuais de gordura e maior marmoreio que os animais não-suplementados. Segundo LUCHIARI FILHO (2000), a gordura intramuscular influencia positivamente a maciez da carne. A diferença na maciez entre inteiros e castrados foi semelhante ao observado por PURCHAS et al. (2002), que encontraram maior valor de força de cisalhamento para os animais inteiros do que para os castrados.

Não houve diferença estatística $(\mathrm{P}>0,05)$ para marmoreio entre animais inteiros e castrados. Este resultado discorda dos observados por VAZ et al. (2001) e RIBEIRO et al. (2004), que verificaram maior marmoreio para os castrados do que para os inteiros. Em relação à cor da carne, os resultados concordam com os observados por RIBEIRO et al. (2004), que também não observaram diferenças entre inteiros e castrados.

Tabela 2 - Área de olho de lombo, espessura de gordura subcutânea sobre a $12^{\underline{a}}$ costela e as respectivas proporções para $100 \mathrm{~kg}$ de carcaça, de acordo com o tratamento e o sexo.

\begin{tabular}{lccc}
\hline Efeito & Área de olho de lombo $\left(\mathrm{cm}^{2}\right)$ & Área olho de lombo $\left(\mathrm{cm}^{2}\right) / 100 \mathrm{~kg}$ carcaça & Espessura de gordura $(\mathrm{mm})$ \\
\hline Tratamento & 77,65 & 30,50 & 4,20 \\
SUP & 77,48 & 30,24 & 2,17 \\
NSU & 0,9661 & 0,8394 & 0,3253 \\
Probabilidade & & \\
Sexo & 81,18 & $32,81^{\mathrm{a}}$ & 2,20 \\
$\quad$ Inteiro & 73,96 & $27,93^{\mathrm{b}}$ & 4,17 \\
Castrado & 0,1008 & 0,0045 & 0,3422 \\
Probabilidade & 8,28 & 6,82 & 100,39 \\
CV $(\%)^{*}$ & & & \\
\hline
\end{tabular}

${ }^{\mathrm{a}, \mathrm{b}}$ Médias seguidas de letras diferentes na coluna, para o mesmo efeito, diferem $(\mathrm{P}<0,05)$ pelo teste $\mathrm{F}$.

${ }^{*}$ Coeficiente de variação. 
Tabela 3 - Comprimentos de carcaça (CC), perna (CP) e braço (CB), espessura de coxão (EC), perímetro de braço (PB) e conformação (CO) da carcaça, de acordo com o tratamento e o sexo.

\begin{tabular}{|c|c|c|c|c|c|c|}
\hline Efeito & $\mathrm{CC}(\mathrm{cm})$ & $\mathrm{CP}(\mathrm{cm})$ & $\mathrm{CB}(\mathrm{cm})$ & $\mathrm{EC}(\mathrm{cm})$ & $\mathrm{PB}(\mathrm{cm})$ & $\mathrm{CO}^{*}$ \\
\hline \multicolumn{7}{|l|}{ Tratamento } \\
\hline SUP & 133,88 & 88,39 & $44,56^{\mathrm{a}}$ & 27,24 & 34,69 & 5 \\
\hline NSU & 131,83 & 86,73 & $42,73^{b}$ & 27,18 & 36,64 & 5 \\
\hline Probabilidade & 0,4237 & 0,1846 & 0,0253 & 0,9420 & 0,1082 & 1,0000 \\
\hline \multicolumn{7}{|l|}{ Sexo } \\
\hline Inteiro & $136,54^{\mathrm{a}}$ & 86,71 & 43,67 & 26,67 & 36,75 & 5 \\
\hline Castrado & $129,17^{\mathrm{b}}$ & 88,42 & 43,62 & 27,75 & 34,58 & 5 \\
\hline Probabilidade & 0,0139 & 0,1989 & 0,9583 & 0,1937 & 0,0929 & 0,5956 \\
\hline $\mathrm{CV}(\%)^{* * *}$ & 3,95 & 2,91 & 3,59 & 5,89 & 6,70 & 12,03 \\
\hline
\end{tabular}

${ }^{\mathrm{a}, \mathrm{b}}$ Médias seguidas de letras diferentes na coluna, para o mesmo efeito, diferem $(\mathrm{P}<0,05)$ pelo teste $\mathrm{F}$.

*Variação de 1 a 6 , sendo 4 = Retilínea, $5=$ sub-convexa e $6=$ convexa.

*** Coeficiente de variação.

$\mathrm{Na}$ tabela 5 , pode ser observado que não foram detectadas diferenças $(\mathrm{P}>0,05)$ para a composição química da carne entre os animais dos tratamentos SUP e NSU. Porém, para os sexos, observou-se que os animais castrados apresentaram maiores percentagens de proteína e extrato etéreo. A maior percentagem de extrato etéreo pode ser atribuída à maior proporção de gordura na carcaça destes animais em relação aos inteiros. Foram observadas maiores percentagens de umidade na carne dos animais inteiros. LUCHIARI FILHO (2000) afirmou que a carne dos animais inteiros possui maior capacidade de retenção de água, por manter altos os valores de $\mathrm{pH}$, quando comparada à de animais castrados. Outra explicação seria a presença de maior quantidade de tecido adiposo na carne dos animais castrados, o que diminui a quantidade de água retida devido a esta não se ligar à gordura.

\section{CONCLUSÕES}

A suplementação alimentar no primeiro inverno proporcionou carnes mais macias. Por outro lado, animais inteiros mantidos em pastagem, com ou sem suplementação alimentar apenas no primeiro inverno e abatidos aos 28 meses de idade, apresentaram carnes menos macias.

\section{AGRADECIMENTOS}

À Coordenação de Aperfeiçoamento de Pessoal de Nível Superior (CAPES), pela bolsa concedida a Climaco. Ao Conselho Nacional de Desenvolvimento Científico e Tecnológico ( $\mathrm{CNPq}$ ), pelas bolsas de Produtividade concedidas a Ribeiro e Mizubuti. Ao CNPq e à UEL, pelas bolsas de iniciação científica concedidas a Noro e Tercílio.

Tabela 4 - Cor, marmoreio, quebras de descongelamento (QD) e de cocção da carne (QC), resistência das fibras ao corte medida pela força de cisalhamento de acordo com o tratamento e o sexo.

\begin{tabular}{|c|c|c|c|c|c|}
\hline Efeito & Cor * & Marmoreio $^{* *}$ & QD $(\%)$ & $\mathrm{QC}(\%)$ & Força Cisalhamento (kgf) \\
\hline \multicolumn{6}{|l|}{ Tratamento } \\
\hline SUP & 4,02 & 4,68 & 8,40 & 34,77 & $6,41^{\mathrm{a}}$ \\
\hline NSU & 3,50 & 2,17 & 7,91 & 34,97 & $7,66^{\mathrm{b}}$ \\
\hline Probabilidade & 0,4018 & 0,1159 & 0,4823 & 0,7798 & 0,0001 \\
\hline \multicolumn{6}{|l|}{ Sexo } \\
\hline Inteiro & 3,85 & 2,85 & 7,86 & 35,05 & $7,50^{\mathrm{b}}$ \\
\hline Castrado & 3,67 & 4,00 & 8,45 & 34,70 & $6,57^{\mathrm{a}}$ \\
\hline Probabilidade & 0,7599 & 0,4448 & 0,3980 & 0,6187 & 0,0004 \\
\hline $\mathrm{CV}(\%)^{* *}$ & 25,81 & 69,78 & 13,20 & 3,18 & 8,60 \\
\hline
\end{tabular}

${ }^{\mathrm{a}, \mathrm{b}}$ Médias seguidas de letras diferentes na coluna, para o mesmo efeito, diferem $(\mathrm{P}<0,05)$ pelo teste $\mathrm{F}$.

${ }^{*}$ Variação de 1 a 5 , sendo 3 = vermelha levemente escura, 4 = vermelha, 5 = vermelho viva.

** Variação de 1 a 18, sendo 1-3 = traços, 4-6 = leve.

${ }^{* * *}$ Coeficiente de variação. 
Tabela 5 - Percentagens de umidade, extrato etéreo, proteína e cinzas no músculo Longissimus, de acordo com o tratamento e o sexo.

\begin{tabular}{llcc}
\hline Efeito & Umidade $(\%)$ & Extrato etéreo $(\%)$ & Proteína $(\%)$ \\
\hline Tratamento & & & 20,84 \\
SUP & 75,63 & 4,94 & 20,58 \\
NSU & 75,58 & 3,60 & 0,6482 \\
Probabilidade & 0,8861 & 0,1903 & 4,44 \\
Sexo & & & $19,96^{\mathrm{b}}$ \\
Inteiros & $76,01^{\mathrm{a}}$ & $2,66^{\mathrm{b}}$ & $21,46^{\mathrm{a}}$ \\
Castrados & $75,20^{\mathrm{b}}$ & $5,88^{\mathrm{a}}$ & 0,8642 \\
Probabilidade & 0,0460 & 0,0088 & 0,0276 \\
CV $(\%)^{*}$ & 0,74 & 35,24 & 4,43 \\
\hline
\end{tabular}

${ }^{\mathrm{a}, \mathrm{b}}$ Médias seguidas de letras diferentes na coluna, para o mesmo efeito, diferem $(\mathrm{P}<0,05)$ pelo teste $\mathrm{F}$.

${ }^{*}$ Coeficiente de variação.

\section{REFERÊNCIAS}

ESPEJO, M. et al. Morfologia de la canal bovina. In: CAÑEQUE, V.; SAÑUDO, C. Metodologia para el estudio de la calidad de la canal y de la carne en rumiantes. Madrid: Instituto Nacional de Investigación y Tecnologia Agraria y Alimentaria, 2000. Cap.2, p.68-80.

EUCLIDES FILHO, K. et al. Efeito da suplementação com concentrado sobre idade de abate e características de carcaça de bovinos Nelore. Revista Brasileira de Zootecnia, Viçosa, v.26, n.6, p.1096-1102, 1997.

GERRARD, D.E. et al. Collagen stability, testosterone secretion and meat tenderness in growing bulls and steers. Journal of Animal Science, Champgain, v.65, n.5, p.1236-1242, 1987.

HANKINS, O.G.; HOWE, P.E. Estimation of the composition of beef carcasses and cuts. Washington, DC: USDA, 1946. 926p. (Tech. Bulletin, 926).

LUCHIARI FIlHO, A. Pecuária da carne bovina. São Paulo: A. Luchiari Filho, 2000. 134p.

MACEDO, M.P. et al. Características de carcaça e composição corporal de touros jovens da raça nelore terminados em diferentes sistemas. Revista Brasileira de Zootecnia, Viçosa, v.30, n.5, p.1610-1620, 2001.

MOLETA, J.L.; PEROTTO, D. Desempenho e características de carcaça de novilhos inteiros ou castrados ao entrar para o confinamento. In: REUNIÃO ANUAL DA SOCIEDADE BRASILEIRA DE ZOOTECNIA, 35., 1998, Botucatu, SP. Anais... Botucatu: SBZ, 1998. V.4, p.671-673.

MÜLlER, L. Normas para avaliação de carcaças e concurso de carcaças de novilhos. Santa Maria: UFSM, 1980 (Publicação n.1).

MÜLLER, L.; PRIMO, A.T. Influência do regime alimentar no crescimento e terminação de bovinos e na qualidade da carcaça. Pesquisa Agropecuária Brasileira, Brasília, v.21, n.4, p.876$888,1986$.

PACHECO, P.S. et al. Características quantitativas da carcaça de novilhos jovens e superjovens de diferentes grupos genéticos. Revista Brasileira de Zootecnia, Viçosa, v.34, n.5, p.1666$1677,2005$.
PAULINO, P.V.R. et al. Validação das equações desenvolvidas por Hankins e Howe para predição da composição da carcaça de zebuínos e desenvolvimento de equações para estimativa da composição corporal. Revista Brasileira de Zootecnia, Viçosa, v.34, n.1, p.327-339, 2005.

PURCHAS, R.W. et al. Effects of growth potential and growth path on tenderness of beef longissimus muscle from bulls and steers. Journal of Animal Science, Savoy, v.80, p.3211$3221,2002$.

RESTLE, J. et al. Evolução do peso de bovinos de corte inteiros ou castrados em diferentes idades. Pesquisa Agropecuária Brasileira. Brasília, v.29, n.10, p.1631-1635, 1994.

RESTLE, J. et al. Machos não-castrados para produção de carne. In: RESTLE, J. et al. Confinamento, pastagens e suplementação para a produção de bovinos de corte. Santa Maria: UFSM, 1999. Cap.10, p.215-231.

RESTLE, J.; VAZ, F.N. Aspectos quantitativos da carcaça de machos hereford, inteiros e castrados, abatidos aos quatorze meses. Pesquisa Agropecuária Brasileira, Brasília, v.32, n.10, p.1091-1095, 1997.

RIBEIRO, E.L.A. et al. Growth and carcass characteristics of pasture fed LHRH immunocastrated, castrated and intact Bos indicus bulls. Meat Science, Exeter, v.68, p.285-290, 2004.

RODRÍGUEZ, V.C. et al. Avaliação da composição corporal de bubalinos e bovinos através do ultrassom. Ciências Agrotécnicas, v.25, n.5, p.1174-1184, 2001.

SANTOS, E.D.G. et al. Influencia da suplementação com concentrados nas características de carcaça de bovinos F1 Limousin-Nelore, não castrados, durante a seca, em pastagens de Brachiaria decumbens. Revista Brasileira de Zootecnia, Viçosa, v.31, n.3, supl.1, p.1823-1832, 2002.

SAS INSTITUTE. SAS/STAT User's guide. Cary: SAS Institute, 1994. V.2.

SILVA, D.J.; QUEIROZ, A.C. Análise de alimentos: métodos químicos e biológicos. Viçosa: UFV, 2002. 235p.

VAZ, F.N. et al. Qualidade e composição química da carne de bovinos de corte inteiros ou castrados de diferentes grupos genéticos Charolês $x$ Nelore. Revista Brasileira de Zootecnia, Viçosa, v.30, n.2, p.518-525, 2001. 